Hussey, L., \& Campbell-Meier, J. (2020). Are you mentoring or coaching? Definitions matter.

Journal of Librarianship and Information Science. https://doi.org/10.1177/0961000620966651

\title{
Are you mentoring or coaching? Definitions matter
}

\begin{abstract}
New library and information science (LIS) professionals, without previous experience in information organizations, are often left adrift, unsure how to apply theory or best practice to a new work environment. To bridge this gap, mentoring and coaching opportunities are often employed (or mandated) to provide new practitioners with required skills, knowledge, or networking. There are opportunities to harness implicit and explicit learning through experiences and interactions through mentoring and coaching. Definitions of mentoring and coaching in the profession are often used interchangeably when discussing the growth and development of an individual. This leads to the questions:
\end{abstract}

- How do librarians define both mentoring and coaching?

- How do mentoring and coaching relate to professional development?

To address the research question, forty-seven semi-structured interviews were conducted with librarians in Canada, New Zealand, and the United States between 2015 and 2016. Participants were asked about their mentoring and coaching experiences. During the interviews, participants were asked questions about their experiences as a mentor or mentee. In addition, participants were asked to define both "mentoring" and "coaching". The authors used an inductive approach to data analysis, interviews were coded by category. 


\section{Introduction}

New library and information science (LIS) professionals, without previous experience in information organizations, are often left adrift, unsure how to apply theory or best practice to a new work environment. Library leaders often note that students may have difficulties applying knowledge and theory into practice (Carlin, 2009, Dali and Caidi, 2016, Nguyen and Hider, 2018).The gap between the explicit and tacit knowledge expected within an organisation (Lancaster, 2003; Kellam and Thompson, 2016) and knowledge gained from reading theory and evidence based practice in the classroom has led to a plethora of "what I didn't learn in library school” articles (e.g.Tumlin, Collins, La Rooy, and Steeves, 2003; Dimunation, M., 2006; Rubenstein, 2017; Cronk and Fleming, 2018). To bridge this gap, mentoring and coaching opportunities are often employed (or mandated) to provide new practitioners with required skills, knowledge, or networking.

Mentoring and coaching are related concepts focused on professional development with different focus and intent. According to dictionary definitions, mentoring generally includes “employee training system under which a senior or more experienced individual (mentor) is assigned to act as an advisor, counselor, or guide to a junior trainee" including providing "feedback and support" for the mentee (Mentor, n.d.). In most disciplines, particularly those focused on professional degrees, mentoring is seen as an important contributor to career development (Pierson, Goulding, and Campbell-Meier, 2019; Campbell-Meier and Hussey, 2019; Hussey, 2016). This usually manifests as professional organizations and educational programs offering formal mentoring programs (Markova et al, 2013; Sugimoto, 2012). In addition to formal programs, informal or situational mentoring relationships develop based on interactions, intellectual interests, and personal chemistry. Regardless of the type of relationship, 
mentoring is generally perceived as a senior or experienced professional working with or guiding someone new to the profession.

Coaching is another important concept for developing professionals, usually aimed at well-defined goals such as successfully completing a probationary period or acquiring specific skills. Coaching, as defined within an organization, focuses on "traditional training methods...and impartial, non-judgmental feedback on performance" (Coaching, n.d.). As with mentoring, coaching often involves senior professionals providing guidance for someone who needs to develop a specific skill or attribute.

There are opportunities to harness implicit and explicit learning through experiences and interactions through mentoring and coaching. Mentoring is often described in terms of unspoken and implied benefits. For example, mentors may provide explicit advice on navigating an organisation and help identify opportunities, while tacitly encouraging and directing the building of a professional network. Coaching, on the other hand, is generally aligned with clearly defined expectations and outcomes. Coaches may assist with setting goals and helping develop a specific skill needed for a position. Both are explicit actions which can tacitly contribute to improvement and growth when new opportunities arise.

Definitions of mentoring and coaching in the profession are often used interchangeably when discussing the growth and development of an individual. This leads to the questions:

- How do librarians define both mentoring and coaching?

- How do mentoring and coaching relate to professional development? 


\section{Literature Review}

Mentoring and coaching are both perceived important, yet there is not a definitive definition of either within the LIS professions. Within the LIS literature, there are common themes regarding both coaching and mentoring, both focus on career skills and growth and discuss training and feedback. For example, mentoring relationships are "... a way to pass along vital skills to new librarians that traditional LIS education cannot offer" (Hicks, 2011, p. 66) and "focused on the individual including skill development, career advancement, and navigating an organization or profession" (Farrell, 2019, p424). Martinez (2014) notes “[t]he goal of coaching is to develop and improve job skills. The goal of mentoring is to encourage positive growth in the young adult" (p558).

In both the general literature and within LIS, it is assumed that mentoring is primarily a one-way and hierarchical relationship, focused on an experience or senior professional sharing advice and knowledge with a new or less experienced individual (Mentoring, n.d.; Higgins and Kram, 2001; Hicks, 2011). "In the conventional mentoring relationship, an older and more experienced mentor passes on skills, advice, and institutional knowledge to a younger and less experienced mentee." (Neyer and Yelenick, p. 215). Within this basic concept, a mentor is always a more experienced individual who can provide support in the development of another (Higgins and Kram, 2001). Reciprocal relationships do, however, develop from mentoring opportunities, providing long term support and feedback for both parties involved (Farrell, 2019). Reczek (2018) notes that within a mentoring relationship "one person takes on the role of listening and providing advice and guidance" and provide "just-in-time advice" (p14). As the mentoring relationship develops, mentees may become more engaged, acting as the listener and providing advice and feedback, providing reciprocal learning opportunities. 
Mentoring programs may be formal or informal. Formal mentoring programs are often associated with new hires or with new members of a professional organization (McHone-Chase, 2015). Farrell (2019) also notes that "[m]entoring can help to reduce isolation or loneliness for a new librarian who is meeting new colleagues and figuring out how to navigate an unfamiliar organization" (p425). Informal mentoring often occurs more organically and is based on mutual interests and support (McHone-Chase, 2015; Reczek, 2018). While formal mentoring programs may be held for a specific time frame, informal mentoring is open-ended.

The professional and career development of a new hire is also often considered a supervisory and management responsibility. This may lead to some of the confusion between mentoring and coaching. Supervisors are accountable to the larger organization while mentors are not (Hicks, 2011). Farrell (2019) notes that supervisors may become mentors, but acknowledges that the supervisor is accountable to the organization, not the mentee. In essence, this implies that supervisors cannot act as mentors, though by the definition of a mentor, there is an expectation that mentors will hold positions of influence over their mentees. Both mentors and coaches provide feedback, though a mentor may focus on feedback about one's career or a specific issue, while a coach provides feedback around skills and performance (Reczek, 2018). If supervisors are not mentors, it suggests that supervisors are coaches.

Coaching, on the other hand, is often directly tied with supervision and the organization rather than the profession. It is defined as a "guided development process led by a coach" (Mcray, 2015) that is "conducted by colleagues, superiors, or specialist trainers, lasting perhaps six to twelve months" (Law, 2011). While the idea of partnership may be implied, the relationship is clearly expected to be built from the organizational hierarchy. Other definitions focus on the individual, Grant (2001) discusses the cognitive, emotional, and behavioral changes 
inherent in coaching and Whitmore (1995) stressed the process as a way to unlock a person's potential. Within the LIS literature, coaching is often practically discussed in terms of staff development, focusing on skills and job performance (Reczek, 2018). Macmillan (2011) identifies coaching as "an interactive process and partnership that builds positive connections between managers and staff'(p2). Much of the literature on coaching is anecdotal and primarily focuses on staff, although a few articles provide empirical evidence about coaching and its benefits.

Mentoring is widely discussed in the LIS literature, but there is not a definitive definition of mentoring. Coaching, on the other hand, is not covered as often as mentoring and tends to focus more on paraprofessional staff development and motivation. Articles and research on coaching are more often published in trade publications whereas mentoring research is generally found in peer reviewed journals (e.g. Journal of Education for Library and Information Science, Journal of Academic Librarianship, and Journal of Library Administration). According to the the literature, there are overlapping attributes of mentoring and coaching as identified in Figure 1.

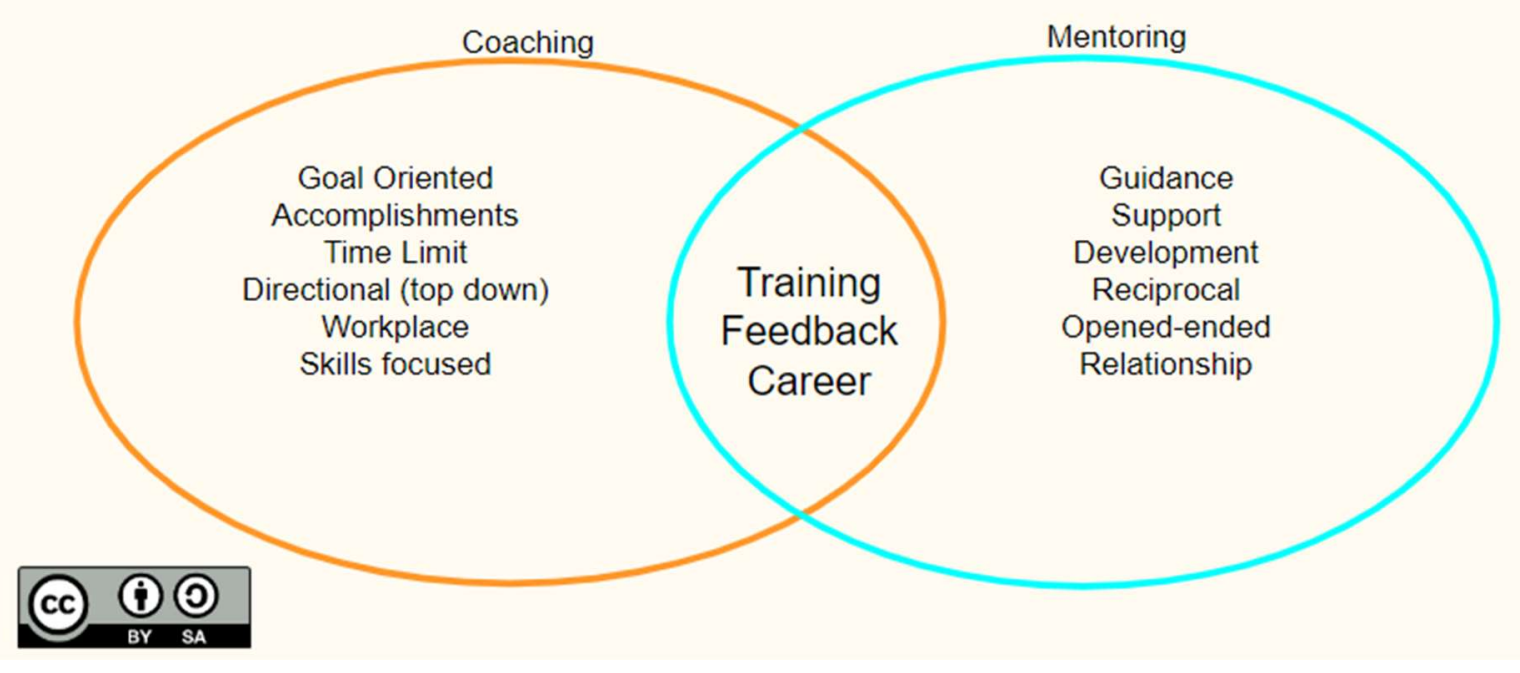

Figure 1 Mentoring and Coaching Attributes from the LIS Literature 
The grey areas between mentoring and coaching introduce questions regarding the differences between the concepts in a professional environment. Goals, such as introducing an individual to a new work culture or developing a specific skill set, are often referred to as coaching rather than mentoring (Malling et. al., 2020; Cheloha, 2012). Long term goals are almost always defined as part of mentoring. Long term goals include career development, from the initial job search through pursuing promotions or tenure. In contrast, coaching is expected to have a finite timeline, often focused on a specific goal, addressing an issue or directed at job performance (Cheloha, 2012; Brown, 2018; Nguyen et. al., 2019).

\section{Methodology}

To address the research question, forty-seven semi-structured interviews were conducted via Skype with librarians in Canada and the United States and in person in New Zealand. . The interviews, conducted between 2015 and 2016, took 15-70 minutes depending on the participants experiences and their availability. The average interview was approximately 45 minutes. During the interviews, participants were asked questions about their experiences as a mentor or mentee. In addition, participants were asked to define both "mentoring" and "coaching". Definitions were followed by questions probing into the mentoring experiences of the participants. The semistructured interview questions included, but were not limited to the following questions:

- How do you define mentoring?

- Do you have a mentor(s)?

- Do you consider yourself a mentor?

- How did you meet or connect with your mentor(s)?

- How does your mentor support you?

- How do you define coaching? 
- What is the difference between mentoring and coaching?

The authors used an inductive approach to data analysis, interviews were coded by category. Codes were developed from themes developed through the analysis, using a grounded approach allowing themes to emerge from the data. The authors reviewed data and identified observable trends that could be used for coding. The authors compared and discussed the trends topics, which were then used to sort data for theme development. The trend topics either became themes or were grouped together within categories using NVivo. After reviewing definitions of mentoring and coaching, the authors identified themes within the definitions around time (longterm versus short term), sentiment, relationships, and goals. A sub-theme, Timeline, was left within the Theme category. While we view time as an attribute of the mentoring relationship, we did not want to lose access to time as discussed in formal and informal mentoring relationships. Working collaboratively, transcripts coded over the course of a week. Topics and categories were revised based on the themes from the definitions. A small number of responses were placed in 2 categories when the researchers could not come to an agreement, however for final analysis the authors chose to review the Theme that best fit the response. See Tables 1 and 2 for the themes.

Table 1: Mentoring Themes

\begin{tabular}{|l|l|}
\hline \multicolumn{1}{|c|}{ Theme } & \multicolumn{1}{c|}{ Concepts } \\
\hline Feedback & $\begin{array}{l}\text { Advice, Constructive/Critique, Questions, } \\
\text { Honesty, Guidance, Transparency, Non- } \\
\text { Judgmental, Safety }\end{array}$ \\
\hline Relationship & $\begin{array}{l}\text { Formal/Informal, Emotional, Personal, } \\
\text { Investment, Challenging, Growth, Quality, } \\
\text { Inspiration, Intellectual Chemistry, Trust, } \\
\text { Reciprocal }\end{array}$ \\
\hline
\end{tabular}




\begin{tabular}{|l|l|}
\hline Seeking/Enabling & $\begin{array}{l}\text { Driven by Mentor/Mentee, Initiated by } \\
\text { Mentor/Mentee, Experience, Modeling } \\
\text { Behaviors, Professional Responsibility, Early } \\
\text { Career/Hierarchical/Age/Experience }\end{array}$ \\
\hline Timeline & $\begin{array}{l}\text { Open Ended (Informal), Expected Ending } \\
\text { (Formal), Not Situational }\end{array}$ \\
\hline Workplace & At Workplace, Not at Workplace, Supervisor \\
\hline
\end{tabular}

Table 2: Coaching Themes

\begin{tabular}{|l|l|}
\hline \multicolumn{1}{|c|}{ Theme } & \multicolumn{1}{c|}{ Concepts } \\
\hline Goals/Outcomes & $\begin{array}{l}\text { Skills Based, Short Term/Time Defined, } \\
\text { Feedback, Practical and Specific, Transition } \\
\text { in New Setting/New Professional, Sequence } \\
\text { of Interactions, No Personal, Top Down }\end{array}$ \\
\hline Human Resources & $\begin{array}{l}\text { Manager/Supervisor, Team/Organizational } \\
\text { Goals, Current Position, Organizational } \\
\text { Focus, Job Performance, Addressing } \\
\text { Problems }\end{array}$ \\
\hline Sports & $\begin{array}{l}\text { Analogies: Spirit, End of the Season, Skills } \\
\text { Performance, Practice Sessions, Comparison } \\
\text { with Sports (Football, Basketball, Rugby, } \\
\text { Tennis) }\end{array}$ \\
\hline
\end{tabular}

For this paper, we are focusing on the results related to definitions, relationships, and goals associated with mentoring and coaching in the library professions.

\section{Findings}

In the interviews, participants were asked to define both Mentoring and Coaching. These are both concepts that have been defined across many disciplines, including LIS. Our research shows that while there are similarities to discipline specific and dictionary definitions of 
mentoring and coaching, the perceptions of both concepts by LIS professionals is more nuanced, often based on experience.

These definitions generally consider the concepts to be related, but with certain differences in focus and expectation. Coaching emphasizes set goals and almost always has a defined time limit. Mentoring focuses on developing the individual/professional and establishing a relationship. Overlap occurs in regard to training, feedback, and career, all three of which can be important to specific goals and professional development. The participants' definitions of mentoring and of coaching did not reflect the overlap identified in the literature (Figure 2).

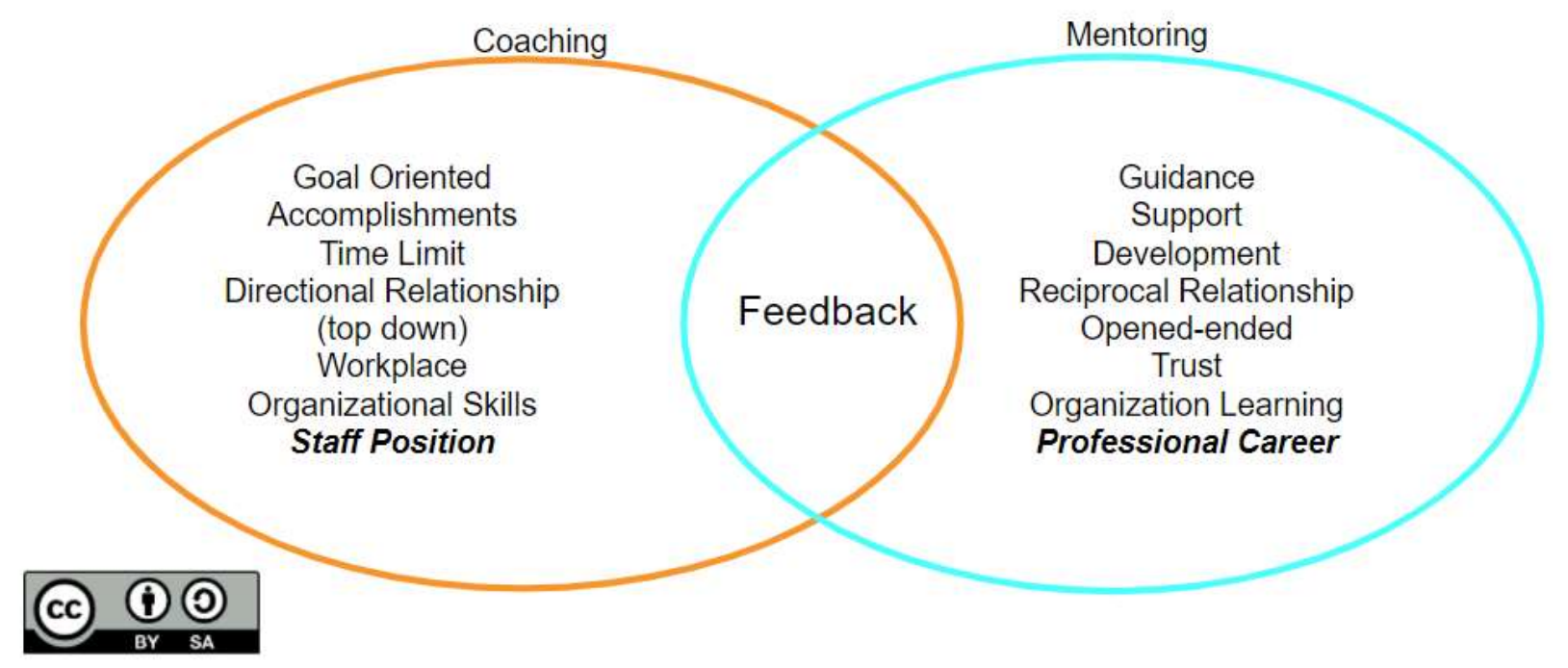

Figure 2 Mentoring and Coaching Attributes from Interviews with LIS Professionals

Unlike the dictionary definitions, the participants' definitions of mentoring and coaching only identified one area of commonality: Feedback. Both mentors and coaches are generally defined or identified as people with more experience and/or skills and would be expected to provide feedback to a less experienced professional. It is the intent and expected use of the feedback that creates the delineation between mentoring and coaching. Training, as perceived by the participants, was more closely related to coaching, often as a tool for skill development, workplace advancement, and other goal-oriented accomplishments. In contrast, mentors provide 
guidance and support for career development beyond the workplace, often described as developing the whole person or providing help with navigating their professional career, providing mental and emotional support, not just training or instruction.

\section{Coaching}

Coaching was most often defined in terms of goals and outcomes. Participants identified two types of coaching experiences, a human resource perspective with an organizational focus and a sports perspective, that focuses on the individual. As noted, the researchers identified themes for both mentoring and coaching. Some themes ${ }^{1}$ were more common than others. The frequency of the coaching themes can be seen in Figure 3.

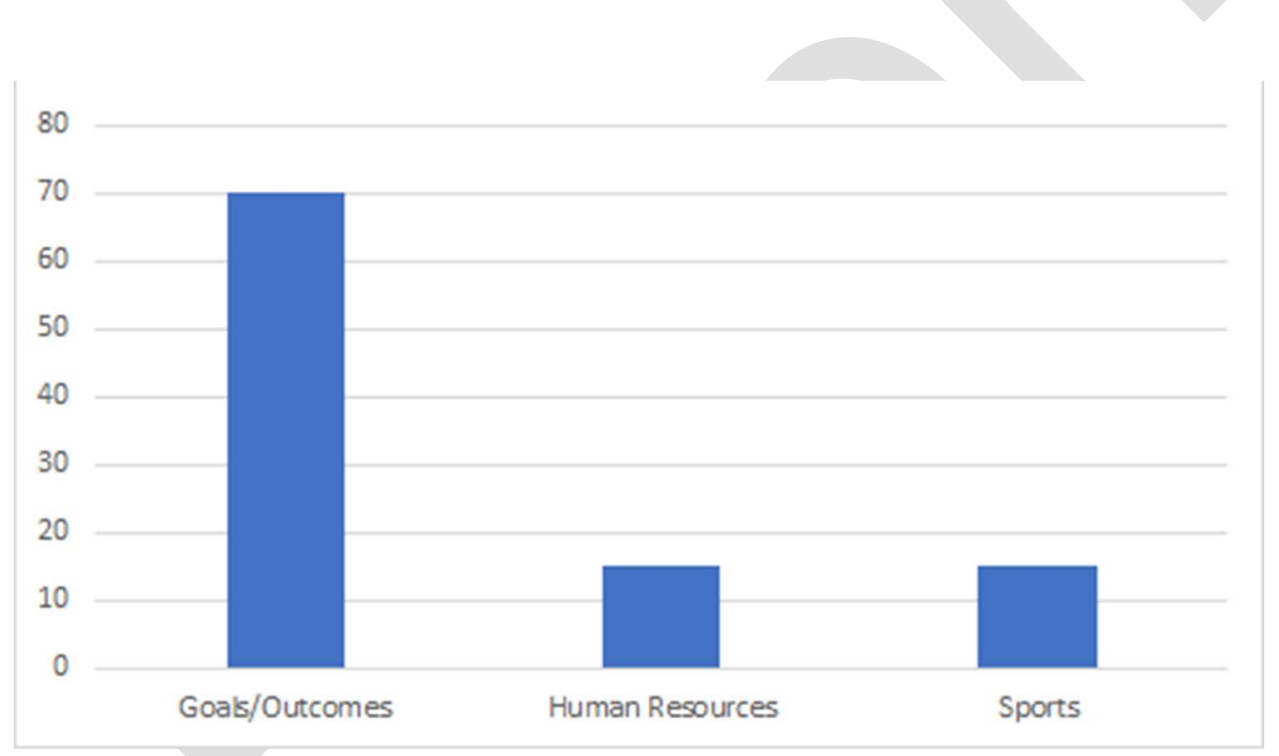

Figure 3 Frequency of Codes for Coaching

\section{Goals and Outcomes}

The major defining characteristic of coaching is the focus on specific goals and outcomes rather than the idea of a more holistic professional development. It is considered "a time defined process... with a specific goal in mind that [someone is] wanting to improve." Goals, more often

\footnotetext{
${ }^{1}$ Some of the definitions had multiple themes. The definitions were broken down and coded for the relevant theme.
} 
than not, have a limited timeline, which is why time was not identified as a theme. Coaching is "short term and more directive" than mentoring, often "specific to one need" or a certain "concrete skill and the specific thing." Coaching often provides a more hands-on approach, considering "tactical nuts and bolts... the approach [to] execute" the skills or goal. Coaching is directed towards "more of the very practical...here's how you do them. The super basic stuff." It may be focused on things like skills, a promotion, or a professional certification and usually has a defined beginning and ending point. Generally, once the goal is met, "that's just it, and you no longer have contact," at least not in terms of the stated goal.

It is often perceived as a more formal and unidirectional process with a "more rigorous connotation... where you sign up for a specific coaching sequence of interactions." Coaching may require scheduling meetings over a certain time period, not unlike when working with a manager or a direct supervisor on a specific goal. Communication in coaching is usually directive and instructive. Unlike with mentoring, coaching feedback is often explicit and prescriptive, expected to be acted upon with the idea of the coach presenting it in terms of "I know what's best." Being a coach necessitates having more experience, and often a higher hierarchical position. " $A$ coach is much more authoritarian and there's much more [of a] rigidly defined hierarchical structure there." It is not about developing the person in terms of the wider profession, but rather focused on a goal. It is an "instrumental and object-oriented activity". One participant noted "I don't necessarily look for a coach to help me deal with...the emotional content of what I'm encountering." While you may still interact or work with a coach once a goal or objective is met, it is not expected to create a deeper or emotional relationship. 


\section{Human Resources}

Among many participants, coaching connected directly to the workplace and to human resources functions. For some, coaching was an enforced process, usually the responsibility of a direct supervisor or manager. The process is intended to "get the best out of the employee...to be able to get team goals, organizational goals, and that kind of thing." It is about the "job they're in now" rather than career aspirations, either within or external to the organization. It may be to help a new employee learn about the organization, provide feedback on job performance, or "when there are problems...where someone is going the wrong way and needs help." Regardless of the reason, coaching is often considered part of a manager's or supervisor's role, possibly dictated by human resources.

Sports

Not surprisingly, the discussion of coaching included references to sports by several participants. These comments aligned with comments about outcomes and goals. "Sort of like if you're an athlete and you're training for an event, a coach is someone there to help you achieve the goal you want... and generally isn't there in the long term." There were also allusions to human resources where "[t] he coach is in control and is just setting the players out to do their bidding" as a manager will direct their employees to do their work. In either case, the coach is expected to focus on the individual, teaching them skills and providing concrete feedback.

\section{Mentoring}

Mentoring was linked closely with professionals and professional development, providing guidance for development. It is expected to be over a longer time period " $n o t$ necessarily attached to the goals of the context in the organization." As one participant noted, "[m]entoring is the need to understand the world or the career or the library that they're going 
to be involved with for, perhaps, the rest of their life." It goes beyond acquiring skills and/or taking on challenges in the workplace, but rather focuses on helping the individual develop into the best version of themselves. Mentoring is "a professional relationship helping someone figure out how to navigate a career." In contrast, coaching was generally tied to an existing workplace, with one participant noting that "coaching comes from managers" while another stated that "coaching is a lot more of a supervisory role." Additionally, coaching focused on defined goals or acquiring specific skills, generally tied to current positions and professional responsibilities.

As noted, the researchers identified themes for both mentoring and coaching. Some themes were more common than others. The frequency of the mentoring themes ${ }^{2}$ can be seen in Figure 4.

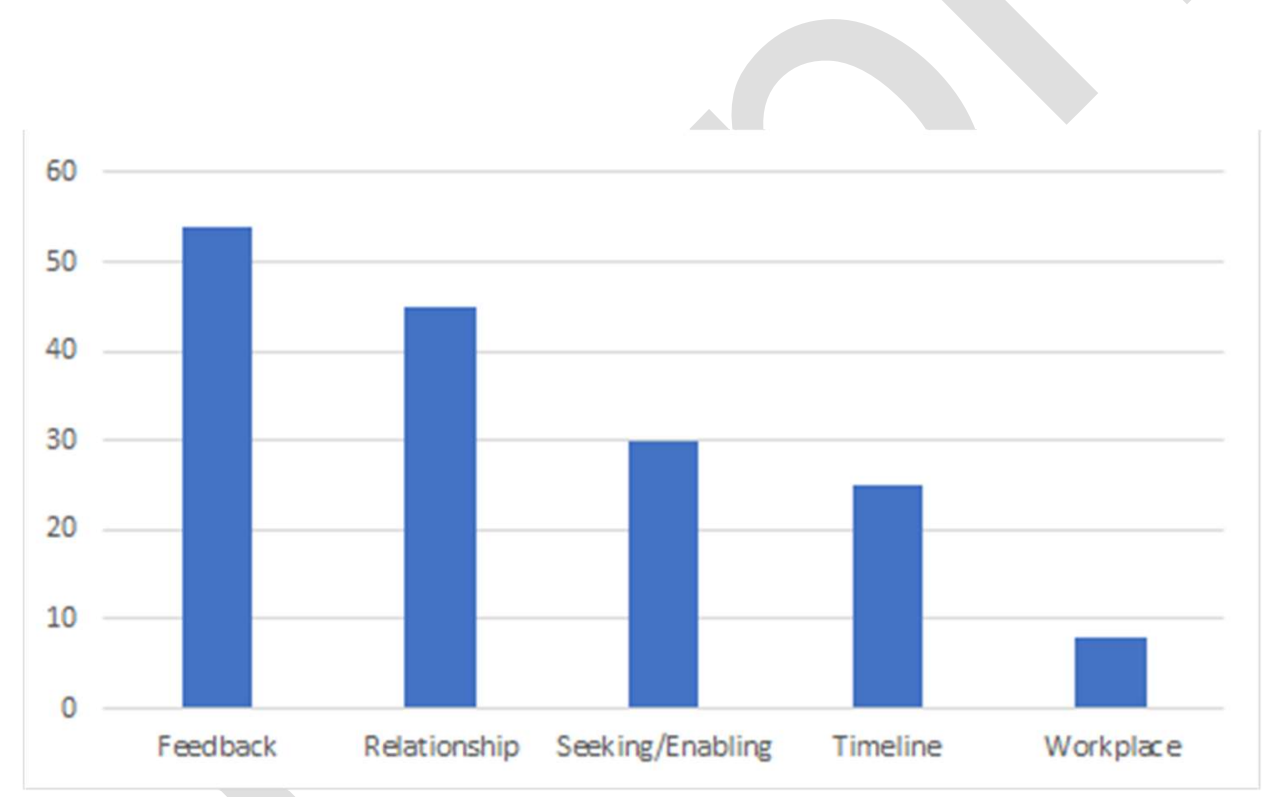

Figure 4: Frequency of Codes for Mentoring

\section{Feedback}

Feedback was the most often discussed aspect of mentoring. However, it was not just about feedback, but rather the type of feedback and expectations of how the information will be

\footnotetext{
${ }^{2}$ Some of the definitions had multiple themes. The definitions were broken down and coded for the relevant theme.
} 
used. "Mentoring is more advice and feedback...it's support." Feedback from mentors is viewed as guidance, provided without expectation or judgement. Mentoring provides a "constructive place for feedback that they might not be able to get in other places." A mentor "is somebody who is willing to be there to hear you out, when you are trying to work through something" and to help create a space "to be able to talk safely about anything." Mentors act as a sounding board and "someone you can go to with questions...even if they don't know the answers, they can at least give you an informed opinion about the questions you might have and...they're not going to put you down." The intent of feedback is to provide opportunity for learning and guidance in a safe place from a trustworthy individual.

Part of what builds trust in a mentor is experience, particularly in terms of the profession and career development. A mentor's experience is an important aspect of providing guidance and feedback, where a "more seasoned professional provides guidance, offers advice, and is just a resource for the newer professional." Mentees may seek guidance from "someone who is experienced in their field" or identify "someone to go to for things that [their] peers can't answer." This experience and knowledge allows a mentor to lay "plain the obscurities of [the] profession... and say 'no, no this is how it works." However, there is not an expectation that a mentor will always have the answers, but rather that they are "someone who's gotten times more context, so if they don't know the answer, they can point you in the right direction." The intent of mentoring feedback is to provide information and guidance, but not necessarily with the expectation that mentees will simply incorporate or adhere to every suggestion or comment.

While much of the discussion of feedback focused on aspects of communication, such as being open to questions, a willingness to listen, and acting as a sounding board, it was more than just communication. Many of the participants stressed the importance of providing honest 
critique and constructive criticism, with one person stating that if "you're going to really mentor someone you'll have to be willing to critique" when it's needed. Mentoring requires one to both "provide advice and/or provide criticism." As one participant noted, mentoring is a "little bit more than just making suggestions, [it's] asking the tough questions in a non-judgemental way." Mentors not only provide support and guidance; they may also identify possible consequences. Ultimately, however, mentees are expected to decide how they will act on the feedback. One participant noted that they viewed “mentoring as a 'here's what I've experienced, and these are my thoughts. You can, of course, apply them as you see fit, but I'm just giving you what I have."” Additionally, the mentoring process is expected to be a dialogue, not just a one-way communication. Part of the mentoring process is to "bounce ideas off each other" and is often "just very conversational."

\section{Relationship}

As a professional relationship, mentors act to "help the mentee not follow one track..., but to help them understand the wider profession and find their own way." Mentees trust mentors to provide good information and mentors trust mentees to listen, ask questions, and then make their own decisions. Many participants described mentoring using terminology such as intimacy, honesty, trust, and commitment. As one person observed, "[m]entorship is definitely communication. I think it's honesty. I think it's transparency. I think it's definitely listening, or someone who's willing to listen. Then if you're not on the right path, or doing the correct thing, maybe they don't say right or wrong, but they're making sure you have every aspect [of information] and not concerned so much with feelings." However, mentoring does include "an element of emotional care" which includes an expectation of privacy and discretion that allows a mentor to provide "very specific pieces of information that [the mentee] couldn't get elsewhere." 
Establishing a relationship allows the mentor and mentee to create an environment where feedback can be shared in a constructive manner both honestly and safely. The relationship is one "that transcends the situation," and includes being "willing to critique when that's the time, praise when it's that time...to be very candid with you and give you the truth." It is not about judgment; it is about sharing experiences and observations, to help someone make good decisions in their career. As one participant observed, "it is a relationship and it is the quality of that relationship" that sets the framework for mentoring. As with any good relationship, in mentoring there is an "intimacy factor" that allows for sharing and trust. Respect also plays an important role. The mentoring relationship is "much more respectful of the mentee as an individual." A mentor should be "concerned with holistic and is looking at the whole person" and is "more overarching and less tangible."

Mentors are generally expected to be more experienced, but the mentoring relationship is not unidirectional and often "more give and take." The mentoring relationship often has a reciprocal aspect, where both parties benefit. It can be a "mutually informative relationship" even if it is initially simply "somebody who is willing to be there to hear you out as you are trying to work through something." As one participant observed, "I think it's best when it is a two-way relationship where both parties know that they're engaged and they feel actively engaged in that relationship." The relationship benefits mentees through knowledge transfer and professional growth. Mentors, on the other hand, benefit by engaging with new ideas and skills introduced by young professionals. As one participant noted "I don't feel like the benefits flow just one direction...the more opportunities. I have to [mentor], the more I feel like the benefits and information sharing comes upward towards me." 
When discussing the mentoring relationship, the participants often made a point to distinguish between informal and formal mentoring. An informal mentoring relationship was seen as indefinite, while a formal relationship was often viewed as having a specific time frame. This was often tied to the idea of building the mentoring relationship. When describing informal mentoring, one participant noted that a mentor is "sort of a constructive friend" who provides guidance to the larger profession. Formal mentoring, on the other hand, is described in more goal-oriented terms such as "helping early career and students...get a leg in the door to the profession" and to help "another to clarify their goals and life objectives." There is also an implicit expectation that mentoring is a professional process, with one participant defining "mentoring as a formal or informal relationship through which knowledge is imparted in a professional situation."

\section{Timeline}

As noted in the Methodology, Timeline was kept as a Theme, though it has attributes associated with Relationships. Participants noted the timeline of both the mentoring process and relationship. Although a few participants felt mentoring could be a onetime incident or interaction where someone provides assistance, generally, they felt it was a long-term process, possibly "several years at the minimum." Mentoring does not take place over a "fixed amount of time" as it requires "a type of investment...that feels longer term." The process is considered "holistic, looking at...the whole professional person and often even beyond professional." One participant talked about mentees they worked with at a previous position that they "still correspond with them and I feel like I will for a long period of time." As a result of the longer timeline, the relationship is not static. The participants are working professionals, and will both 
continue to learn and grow, which then influences and changes the mentoring needs and interactions.

\section{Seeking and Enabling}

Seeking and Enabling comments primarily focused on who was responsible for establishing and driving the relationship, but also touched on who can and should act as mentors. In terms of the relationship, there is "some degree of intentionality" where both mentors and mentees are expected to contribute time and effort. However, not all agreed on who was responsible for the majority of work. Many felt the mentor needed to take on more responsibility in establishing and engaging in the relationship, but some noted that the mentee was who should lead the process. According to these participants, the mentoring process is "very much driven by the mentee," with the expectation that if someone wants to be mentored, they will approach someone who demonstrates "the behavior you're after." However, more implied that the mentor should initiate the relationship by "taking somebody with less experience under their wing." Mentees are still expected "to participate, but...it's also the mentor's job to check up on the person."

While taking on mentoring duties requires time and effort, it can be perceived as " $a$ little bit more altruistic [in that] you're helping people out and it's good for the field and it's good to do it." For some, it is seen as a professional duty, that "once you have hit a level where you are generally comfortable in the profession...it's your duty to do this for the people that come behind you." In this way, mentoring is not only a way to help mentees, it is also a method of improving the field by developing capable and effective professionals. However, it's not always an overt act. Mentoring can also be subtle, where one focuses on "modeling best behaviors, best 
practices" or "where one party is observing another party, perhaps also engaging in conversations."

The seeking and enabling comments also focused on who can mentor and why someone is identified as a mentor. Experience, values, and behaviors were some of the most important characteristics of mentors. Whereas a mentor might be "a person who was about [the same] age" what matters is that a person is "perhaps a little bit older than you are in professional terms...had more time to experience situations in the workplace" that allows them to "share observations...in the hopes of helping [a mentee] deal with whatever [they're] dealing with at the moment." Supervisory or hierarchical positions weren't seen as important as “mentoring can come from anyone" as long as they are able to "provide support for the person in a more psychological and emotional way." However, there was still a sense of a power dynamic or hierarchy. As one participant described mentoring is "a teacher-student relationship, but on a more professional level in which the mentor is someone who is quite well regarded within a particular field."

\section{Workplace}

The final mentoring theme considered the workplace, primarily noting that mentoring went beyond the organization. A mentor is probably "not a person's line manager" and does not revolve "around direct reports." That is not to say, however, that mentors aren't found in the workplace. One participant felt that for new professionals, it was important for the mentor to "be in the building with you, who shows you the ropes, who answers your questions, someone who'd been in that library...and can ease your way in when you're a brand new librarian." Yet, the expectation is that the mentoring will be "less connected to job performance and a specific institution" and be focused on helping "them gain some knowledge and wisdom in their career." Regardless of whether it was described as formal or informal, the participants did not feel that 
mentoring is about the workplace, but about "wider development, not necessarily attached to goals of the context of the organization." This is in stark contrast to coaching.

The differences between mentoring and coaching were summed up well by one participant, stating that "[i]t sort of feels like the difference between having a therapist and having a counselor. One is just somebody to talk to and the other is somebody who is helping you work on a thing." Mentoring requires a better understanding of the whole person, including career goals which may shift and evolve as the process proceeds. Another participant noted that mentoring provided guidance "but not a you must do this, more of a how about this". Coaching, on the other hand, has a defined goal, such as the attainment of a specific skill, attribute, or position "... you must do this." While there is some overlap with mentoring, providing feedback and knowledge transfer, coaching focuses on short-term practical and specific goals.

\section{Discussion}

The discussion of the role of mentoring and coaching, often cited tools for professional development, has both implications for both theory and praxis and may provide yet another bridge to cross the gap between the two. Both mentoring and coaching provide individuals with explicit actions and tacit information they can use to advance in careers. In some cases, professionals need specific guidance or advice in order to develop, others need specific skills or attributes. For some, developing networks and creating social capital are unexpected, yet essential to the next step in professional development. Acknowledging the individual needs and creating opportunities for both mentoring and coaching provides specific information needed for professionals at any level to further their careers.

Structured or formal mentoring was offered through associations and through individual workplaces pairing new members with more experienced individuals. These pairings may have 
specific outcomes from which trust may be gained. However, the formal nature or lack of chemistry between the pairs may limit a development of a true mentoring relationship. While participants found association mentoring helpful for developing social networks, the relationships identified typically did not last through the designated mentoring timeframe. The limitations for building trust based on shorter time periods and unstated expectations often impeded development of stronger relationships. Unstructured or informal mentoring, on the other hand, were frequently identified as long-term relationships. These relationships provided participants with a sounding board and someone they could go to for advice about career planning. Informal mentors could come from professional associations, conferences, workplace, and networks. There wasn't any limitation on where or how an informal mentoring relationship developed. Coaching, on the other hand, may be offered from an individual's organization or from an external provider, working towards "the goals of the organization, the assumptions of the sector, or skill set of the sector." This focus on assumptions about what one needs to know to do a job and skills related to the profession is a point at which formal mentoring and coaching potentially overlap.

Within our interviews, there were several examples of mentoring programs that focused on activities more closely related to Coaching. For example, as one participant described, formal mentoring programs are "where you're given a person's name and their phone number...and maybe you're supposed to check in X number of times." Another observed that their mentoring was actually coaching, "I saw my role as helping that person enter the academic librarianship field, talking about promotion, tenure, faculty versus non faculty status, getting involved in ALA or other associations, joining and chairing committees, publishing to some degree, getting professional development, and so forth." In this case, the focus of the formal mentoring process 
was on specific goals. This is further supported by another participant's description of coaching as "more connected to a specific role, for example, coaching around revisions of an article or around coaching a librarian for senior librarian or something like that." Coaching, whether formal or informal, had a specific goal and is "more skills based as opposed to professional development.". Whether or not the goal contributed to career and/or professional development was irrelevant in determining a successful outcome. What matters is whether or not the goal is achieved. Most participants who discussed coaching typically identified it as a successful process. In comparison, formal mentoring programs without clear outcomes and goals were often identified as less successful by both participants. Mutually identified purpose in a formal program may influence perceived success of the endeavor. Informal mentoring does not appear to need a clear purpose in order to be perceived as successful, this may be due to the further development of a pre-existing relationship or an existing level of trust.

Participants brought up concepts related to the development of trust in a relationship both implicitly and explicitly. For mentoring, it was noted that "you need to pick someone that you can trust, and approach them and negotiate on an individual basis". Trust, especially in terms of confidentiality and privacy, were key to build a relationship and fostered confidence in the advice and training. One participant observed:

...the real mentor thing does give that longer term feel to it. It's based on a relationship of trust, and that's the important thing. I know that I can say things to this person ... and know [that it] won't go anywhere else. This was critical to that sort of relationship.

Mentors and coaches may gain "intangible" benefits as well, "[it] made me feel confident that [the protégé] was very trusting" of the way a mentor/coach handled a situation. Most participants, however, did not explicitly discuss trust, even when prompted. The importance of 
the trust was clear in descriptions of the emotional aspects of coaching and mentoring relationships that resulted from the questions about trust.

Many participants noted key differences between formal/structured and informal/unstructured mentoring. One participant described formal mentoring where "maybe you might speak with a person initially a couple times a year and them maybe once or twice a year you'll touch base after that for a certain number of years." Whereas unstructured/informal mentoring was described as where you "can have pithy, professional conversations" and working with someone who "gives them excitement, interest, and inspires them to explore." However, both provided strong benefits like sounding board, social network, constructive and honest feedback, and a stronger connection to the profession. Informal mentoring was described using terms like inspiration, intellectual chemistry, emotional/personal connection, and trust. These same characteristics were listed as challenges in the formal mentoring process, often due to dealing with assumed expectations of outcomes and a lack of agreement as to who is responsible for driving the process. For example, a mentor might be willing to answer questions, yet mentees might not feel encouraged or able to ask. It can be daunting to approach someone you admire or a person with more experience for fear of being seen as unprepared and/or uninformed. "I think [mentors] sometimes will want the person to come up to them and I don't think a lot of people do it, and i think a lot of people have questions that they're afraid to ask, especially about job stuff because they don't want it to be an inappropriate question, or just sort of out of bound, this is not professional to ask about, or I can't really give you a professional answer, or something like that." While not always successful, formal relationships can develop into a more lasting and mutually beneficial relationship. One participant described how their relationship changed over time and how "not only do I no longer be have to be really formal. I 
don't feel like the benefits flow just one direction." Unlike Coaching, which is expected to end, formal mentoring has the potential to transform into a more complex and beneficial relationship.

Unfortunately, dysfunctional or negative mentoring relationships also occur and have been viewed from both a mentor and protégé perspective (Eby and McManus, 2004; Eby, McManus, Simon, and Russell, 2000). Eby and McManus (2004) identified a continuum of negative relationships from serious problems, such as harassment, to "marginally effective relationships", that identify a protégé's unwillingness to learn (p257). As one participant noted "[t]hat's one of the stressful or negative sides of mentorship in my experience is that sometimes you get stuck with somebody". Even negative experiences can help with learning and development:

I learned a lot from my early bosses but I had bosses who I learned a lot from who were appalling. Just dreadful. I suppose almost anti-mentoring. I don't know how to define that but in some ways you learn as much from a bad boss as you do from a good one. Although, it's a hell of a lot more painful.

While serious problems should be grounds to immediately end a mentoring relationship, marginally effective relationships may develop out of a misunderstanding of the role of the mentor. Hicks (2011) notes that mentoring leaders "needs to be considered fully by looking at both its positive and negative aspects" and that a critical, more "self-reflective and aware approach" is needed for the relationship to develop (p73). As part of this approach, it may be useful for participants in both mentoring and coaching relationships to explicitly define expectations from the relationship.

Coaching definitions varied by participant with some identifying coaching in terms of deficits (improvements needed within the organization) and in terms of development (improvement needs for an individual's advancement within the profession). This focus is more 
"skills based as opposed to professional development" and "more instrumental and object oriented." Unlike much of the literature which mainly focused on coaching students, the perception is that coaching is applicable at various stages in professional development aimed at a certain goal or outcome.

Coaching does not require the coach to be in the profession. Coaches can work with people across an organization to improve in their current position and develop within the context of the organization. "The coaching piece for me is around having someone who isn't even necessarily a librarian help you through some challenging situation...like a facilitator, a teacher" would do. It could be someone in "middle management and that's where you're at and you're looking for someone to help you." In both cases, it is skills for the workplace that are important and may not even require professional knowledge to help someone reach certain goals. "It might be somebody who doesn't have as much experience but might be able to help them navigate those barriers better, but I think it's usually experience." Sometimes the experience isn't in the profession, it's in the organization. In comparison, mentoring often includes working on and providing feedback on skills, but in terms of the wider profession that might be applied in the current workplace.

In LIS, the MLIS is often considered a terminal degree. Yet, the reality is that education can only do so much and there is an expectation of on-the-job learning, both in terms of learning about the organization and the profession. This is where both coaching and mentoring contribute: coaching provides on the job training while mentoring focuses on soft skills. Coaching works towards an established goal whereas mentoring helps "another to clarify their goals." While asked to define the concepts separately, mentoring and coaching were perceived as related by the participants. As one interviewee noted that they viewed "coaching is a subset of mentoring 
where you're actually working on something very specific and they're leading you into a direction or they're giving their opinion or they're even suggesting someone else that you might go to, to get more coaching for that particular aspect." Yet, there were also distinct differences. Coaching was described as "enforced" and a process that "seems more transactional to me, but maybe it's just the professionalization of coaching." Mentoring, on the other hand, was generally described in more relaxed terminology, noting that the process "is more conversational" and may simply be where "there is no problem...just somebody who needs a buddy."

The focus of mentoring and coaching, both in the literature and for most responses, tends to be on early career professionals and/or students. While this stage in professional development can be considered seminal, it is not the only time that professionals need mentoring and coaching. Mid-career is another significant stage in professional development, but it is often not addressed directly or as often as early career. There does seem to be some expectation that early career mentoring helps set one up for further professional development when mentoring is "[t]rying to introduce them to concepts that are maybe a little bit deeper or a little more challenging than someone who is at their experience level would normally have it, just so that [they] are more prepared for those things in the future." However, mentoring or coaching for mid-career development is rarely explicitly stated or addressed.

\section{Conclusion}

New and mid-career professionals often seek out mentors and coaches for career development and progression. Both can contribute greatly to professional and career development, but in different ways. Mentors tend to focus on long-term career development, providing guidance and feedback for the mentee to use as they see fit. The impact of mentoring may be incremental, building and developing over time. Coaching, in contrast, is generally 
aimed at shorter-term goals and specific skill development with an expectation of visible results. Without a better understanding of these concepts, however, professionals may be turning to a mentor when they need a coach, and vice versa. Identifying and defining the specific roles and attributes of coaches and mentors has ramification for both professional practice and continuing professional development.

To that end, we propose the following definitions to the LIS community:

- Mentoring: The open-ended, reciprocal relationship to guide and support the development of one's professional career.

- Coaching: The organizational skills focused, goal-oriented training necessary to develop in one's position.

The way in which we discuss mentoring may actually create challenges and confusion between mentors and protégés, and between coaches and employees. In the LIS literature, mentoring tends to focus more on professionals, while coaching targets staff. Yet, professionals often need coaching, especially in new positions or when taking on new responsibilities. Supervisors are often expected to undertake roles that encompass both coaching and mentoring responsibilities, but the supervisors' responsibility to the organization may impede the development of trust within an organization. While many organizations employ mentoring for new hires, coaches may be better suited to provide the skills new employees need for success. Clear definitions and roles may provide the groundwork for critical reflection on the goals of mentoring and coaching relationships and allow organizations to better utilize the appropriate approaches to professional development. 


\section{References}

Brown, C (2018) In the public interest: Creating better learners through learning science: a sample of methods. Journal of Library Administration 58: 375-381.

Busby, C (2015) Developing library leaders: The New Zealand Approach. New Zealand Library \& Information Management Journal 55(3): 17-23.

Campbell-Meier, J and Hussey, L (2019) Exploring becoming, doing, and relating within the information professions, Journal of Librarianship and Information Science 51(4): 962-973.

Carlin, AP. (2009) Segmented professions: Further considerations of theory and rractice in LIS and librarianship. Library Philosophy \& Practice: 1-15.

Cheloha, RS (2012) Managing the unhappy employee. Contractor Magazine 59(3), 48.

Coaching. (n.d.). Business Dictionary. Available from:

http://www.businessdictionary.com/definition/coaching.html

Cronk, L and Fleming, R (2018) “They didn't teach this in library school”: Identifying core knowledges for beginning acquisitions librarians. Against the Grain 30(6): 13.

Dali, K. and Caidi, N. (2016) A two-way street: building the recruitment narrative in LIS programs. New Library World 117(7/8): 499-539.

Dimunation, M (2006) Red wine and white carpets: What we didn't learn in library school, or when the dog and pony goes bad. RBM: A Journal of Rare Books, Manuscripts, and Cultural Heritage 7(1): 73-84.

Eby, LT and McManus, SE (2004) The protégé's role in negative mentoring experiences. Journal of Vocational Behavior 65(2): 255-275.

Eby, LT, McManus, SE, Simon, SA and Russell, JE (2000) The protege's perspective regarding negative mentoring experiences: The development of a taxonomy. Journal of Vocational Behavior 57(1): 1-21.

Eraut, M (2004) Informal learning in the workplace. Studies in Continuing Education 26(2): 247-273.

Evans, L (2019) Implicit and informal professional development: What it 'looks like', how it occurs, and why we need to research it. Professional Development in Education 45(1): 3-16. 
Farrell, M (2019) Leadership reflections: Who are your peeps? Journal of Library Administration 59(4): 422-430.

Grant, AM (2001) Towards a psychology of coaching. Sydney: University of Sydney Coaching Psychology Unit.

Hicks, D (2011) The practice of mentoring: Reflecting on the critical aspects for leadership development. The Australian Library Journal 60(1): 66-74.

Higgins, MD and Kram, KE (2001) Reconceptualizing mentoring at work: A developmental network perspective. The Academy of Management Review 26(2): 264-288

Hussey, L and Campbell-Meier, J (2016). Developing professional identity in LIS. Education for Information 32: 343-357.

Kellam, L and Thompson, K (2016). Databraianship: The academic data librarian in theory and practice. Chicago: Association of College and Research Libraries.

Lancaster, FW (2003) Indexing and abstracting in theory and practice, 3rd ed. Champaign: University of Illinois Press.

Law, J (2011). Executive coaching. In Business: the ultimate resource (3rd ed.). A\&C Black. Credo Reference

Lee, J, Anderson, A and Burnett, G. (2017) Peer relationships and mentoring between LIS doctoral students: A qualitative approach. Journal of Librarianship and Information Science 49(1): 115-124.

Macmillan, M (2011) A "coach approach" to staff engagement. Partnership: The Canadian Journal of Library \& Information Practice \& Research 6(2): 1-9.

Majid, S (2004) Continuing professional development (CPD) activities organized by library and information study programs in Southeast Asia. Journal of Education for Library and Information Science: $58-70$.

Malling, B, de Lasson, L, Just, E and Stegeager, N (2020) How group coaching contributes to organisational understanding among newly graduated doctors. BMC Medical Education 20(1): NA. Epub. https://doi.org/10.1186/s12909-020-02102-8.

Markova, G, Ford, RC, Dickson, DR and Bohn, TM (2013) Professional associations and members' benefits: What's in it for me? Nonprofit Management \& Leadership 23(4): 491-510. 
Martinez, SL (2014) Training tech services'student employees well: Evidence-based training techniques in conjunction with coaching and mentoring strategies. Cataloging \& Classification Quarterly 52(5): 551-561.

McHone-Chase, S (2016) Mentors make it better...but not all are created equal. ILA Reporter 34(5): 4-6.

Mcray, J (Ed) Coaching. In Leadership glossary: Essential terms for the 21st century. Mission Bell Media.

Mentor (n.d.) Merriam-Webster's Learner's Dictionary. Available at: http://www.merriamwebster.com/dictionary/mentoring.

Mentoring (n.d.) Business Dictionary. Available at:

http://www.businessdictionary.com/definition/mentoring.html

Neyer, L and Yelinek, K (2011) Beyond Boomer meets NextGen: Examining mentoring practices among Pennsylvania academic librarians. The Journal of Academic Librarianship 37(3): 315-221.

Nguyen, CA, Artis, AB, Plank, RE and Solomon, PJ (2019). Dimensions of effective sales coaching: Scale development and validation. Journal of Personal Selling \& Sales Management 39(3): 299-315.

Nyugen, LC and Hider, P (2018) Narrowing the gap between LIS research and practice in Australia. Journal of the Australian Library \& Information Association 67(1): 3-19.

Pierson, CM, Goulding, A and Campbell-Meier, J (2019) An integrated understanding of librarian professional identity. Global Knowledge, Memory and Communication 68(4/5): 413430.

Reber, A (1993) Implicit learning and tacit knowledge an essay on the cognitive unconscious. New York:Oxford University Press.

Reczek, K (2018) Informal mentoring has always worked for me. Information Outlook 22(1): 14.

Rubenstein, EL (2017) " I didn't learn that in library school"—Experiential learning in consumer health for future public librarians. Library Trends 66(1): 37-51.

Sinkinson, C (2011) An assessment of peer coaching to drive professional development and reflective teaching. Communications in Information Literacy 5(1): 9-20. 
Sputore, A, Humphries, P, and Steiner, N (2017) Strength through partnering: new professional development opportunities in academic libraries. In IFLA WLIC, Cape Town, South Africa, 1214 August 2015. Available at: http://library.ifla.org/id/eprint/1920

Stark, J (2018) Battle of the books: Coaching an English high school literary trivia competition in Montreal, Quebec. Education Libraries 41(1): 1-7.

Sugimoto, C (2012) Are you my mentor? Identifying mentors and their roles in LIS doctoral education. Journal of Education for Library and Information Science 53(1): 2-19.

Tumlin, M, Collins, M, La Rooy, P and Steeves, M (2003) Everything I need to know about serials I didn't learn in library school. Serials Review 29(1): 26-35.

Vega García, SA, Stacy-Bates, K.K, Alger, J and Marupova, R (2017) Peer evaluation of teaching in an online information literacy course. Portal: Libraries \& the Academy 17(3): 471483.

Whitmore, J (1995) Coaching for performance: A practical guide to growing your own skills. London: Nicholas Brealey Publishing. 